\title{
ARX, ARMAX, Box-Jenkins, Output-Error, and Hammerstein Models for Modeling Intelligent Pneumatic Actuator (IPA) System
}

\author{
Mohamed Naji Muftah ${ }^{1,2}$, Wong Liang Xuan ${ }^{1}$ and Ahmad Athif Mohd Faudzi ${ }^{1,3 *}$ \\ ${ }^{1}$ School of Electrical Engineering, Faculty of Engineering, Universiti Teknologi Malaysia, Malaysia \\ ${ }^{2}$ College of Electronic Technology-Bani Walid, Libya \\ ${ }^{3}$ Centre for Artificial Intelligence and Robotics (CAIRO), Universiti Teknologi Malaysia, Malaysia
}

\begin{abstract}
A pneumatic actuator is highly nonlinear, which makes the precise position control of this actuator difficult to achieve. In order to achieve precise control, selecting a suitable model structure is a prerequisite before control estimation. This selection of the model structure is based upon an understanding of the physical systems. In this paper, the black-box model is chosen as a system identification model for modeling position control of an Intelligent Pneumatic Actuator (IPA) system and a variety of parametric model structures. The parametric model structure, such as ARX, ARMAX, Box-Jenkins, output-error structures, and Hammerstein available in the black-box model, is used to assist in modeling the IPA system. The results indicate that Hammerstein had the best performance for modeling position control of the IPA system with the best fit 94.95. Also, the results show that ARX, ARMAX, Box-Jenkins, and output-error structures had best fit more than $90 \%$.
\end{abstract}

This is an open access article under the CC BY-SA license

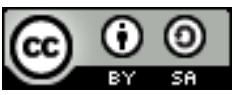

Keywords:

ARMAX;

$A R X$;

Box-Jenkins;

Intelligent Pneumatic Actuator;

System Identification (SI);

\section{Article History:}

Received: July 4, 2021

Revised: November 7, 2021

Accepted: November 11, 2021

Published: November 25, 2021

Corresponding Author:

Ahmad Athif Mohd Faudzi

School of Electrical Engineering,

Faculty of Engineering, Universiti

Teknologi Malaysia, Malaysia

Email:athif@utm.my

\section{INTRODUCTION}

The pneumatic actuator is one form of actuator widely used in industry. The pneumatic actuating mechanism provides the benefits of a high power-to-weight ratio, lightweight, comparatively low cost, smoother maintenance and more straightforward construction than other actuators [1]. Research on pneumatic devices have also been studied solve their nonlinearities, which, due to air compressibility, are high friction forces, dead band, and dead time [2]. In comparison, the main disadvantages of pneumatic actuator systems also find it more difficult to model position control and develop the controller for the system.

The development of an intelligent actuator is a benchmark for advancement in the field of control systems engineering science, as stated in [3]. Suzumori et al. [4], whose works centered on controlling the position and speed of the actuator, first implemented an intelligent actuator system with the development of a servo mechanism in 2005. In 2010, Faudzi et al. [5] developed a new actuator called Intelligent Pneumatic Actuator (IPA) to address the shortcomings of poor precision and force control systems. This actuator incorporates the actuator, microprocessor and sensor in one device.

Many studies have been carried out over the last decade to model the whole pneumatic system. An analysis of previous studies outlined two popular models for the pneumatic method by researchers; one theoretical (first principle) and the experimental $[6,7,8,9,10]$. The second approach to modelling the pneumatic system would concentrate on this analysis. A highly functional solution and easy to work with the complicated system or process are why 
the second approach is preferred $[11,12]$. In addition, there are a few model constructs in system identification that can be used to describe the system [13].

Therefore, the purpose of this analysis is to model the IPA Method using ARX, ARMX, Box-Jenkins, output-error, and Hammerstein model structures and compare them based on best fit and Final Prediction Error (FPE).

\section{METHOD}

A physical view of the intelligent pneumatic actuator (IPA) system used in this research is shown in Figure 1. The IPA device operates well with five main components; the optical sensor, the laser rod, the pressure sensor, the on/off valves, and the programmable chip (PSoC) control board. Each of these components has its own function and is intertwined with each other. For example, to detect the position of the cylinder stroke based on the position reading provided by the laser stripe rod, an optical sensor that has been placed on top of the cylinder will be used $[14,15]$. Other elements, such as the pressure sensor and the on/off valves, also play significant roles in regulating the system. These two elements were primarily used to control the inlet and exit air of the cylinder in order to perform the extension and retraction of the stroke of the cylinder. The action of the IPA machine cylinder stroke depends on the function of the on/off valves. When the off valve is activated, the stroke is retracted. The stroke is extended when the valve is activated.

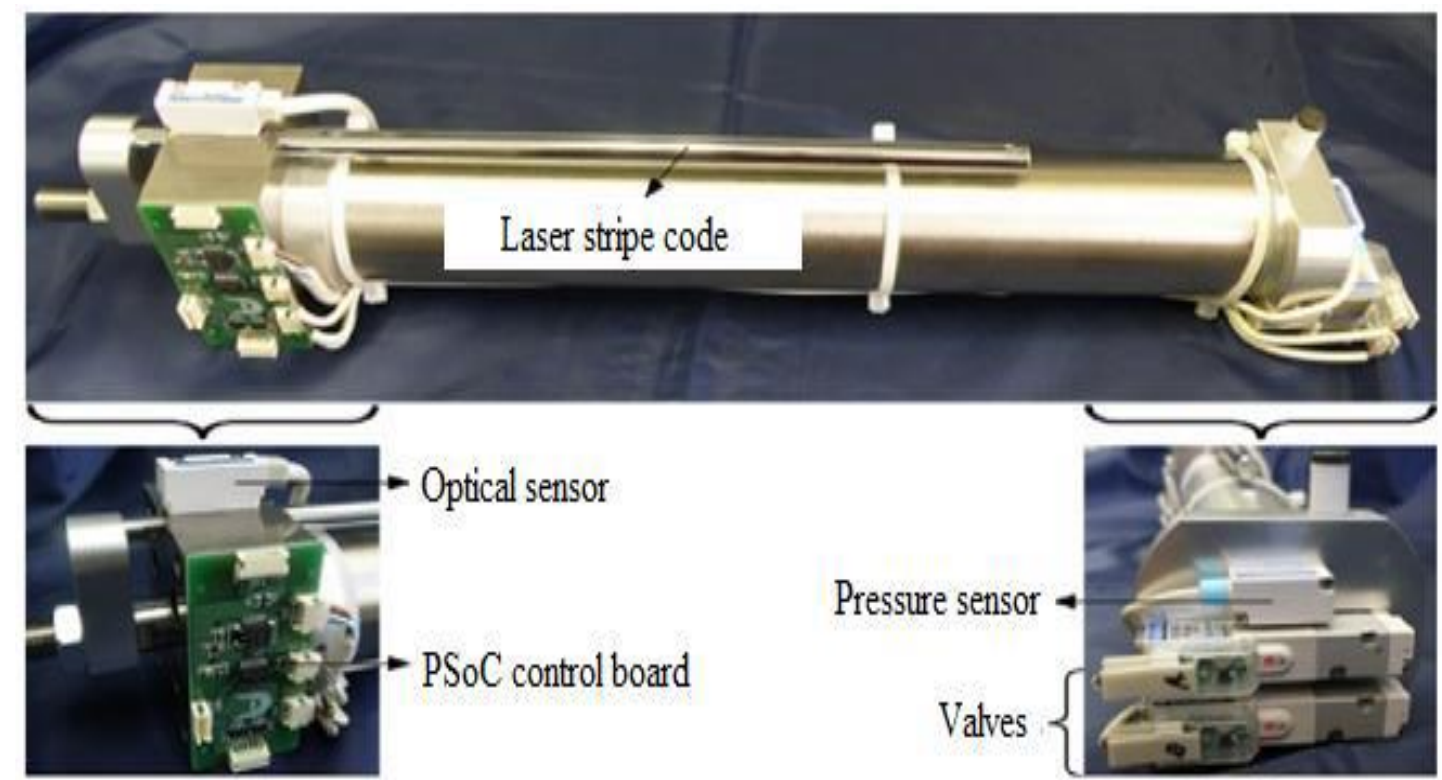

Figure 1. The intelligent pneumatic actuator (IPA) system [7]

\section{Experimental Design and Data Collection}

Figure 2 displays the experimental setup for this research that was used to collect the input and output data. Using the National Instrument (NI) Data Acquisition (DAQ) card PCI/PXI6221 (68-Pin) board, SHC68- 68-EPM cable, and SCB-68 M series modules, the intelligent pneumatic actuator system and personal computer (PC) (equipped with MATLAB software as the platform) interact.

An experiment in real-time was performed using a pneumatic actuator system, and 1500 input and output data measurements were taken from that experiment. The sample time (Ts) used for input and output data processing is 0.01s. Figure 3 shows the plot of input and output data. 


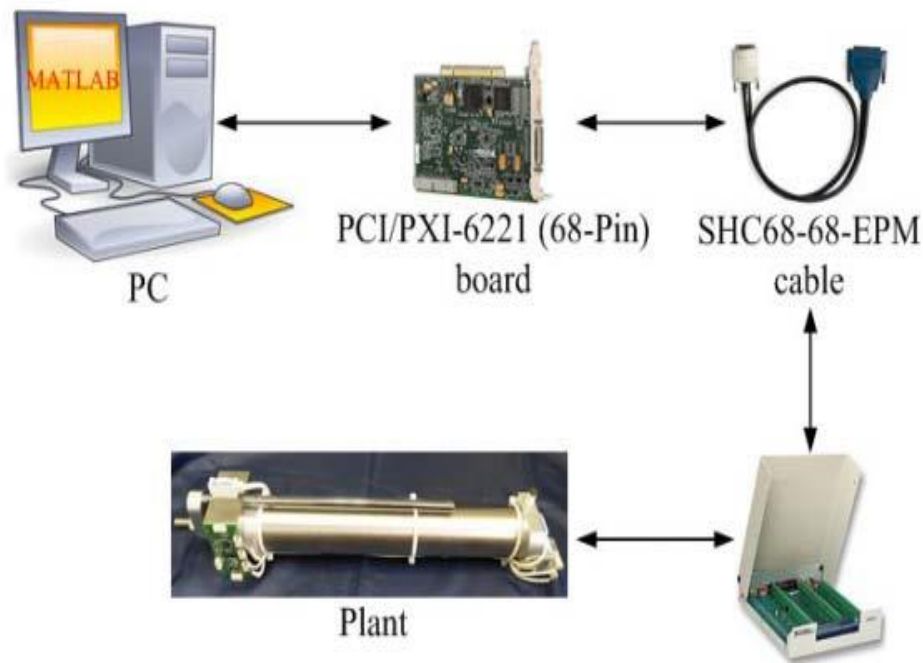

SCB-68 M series

devices

Figure 2. Process of collecting input and output data [16]

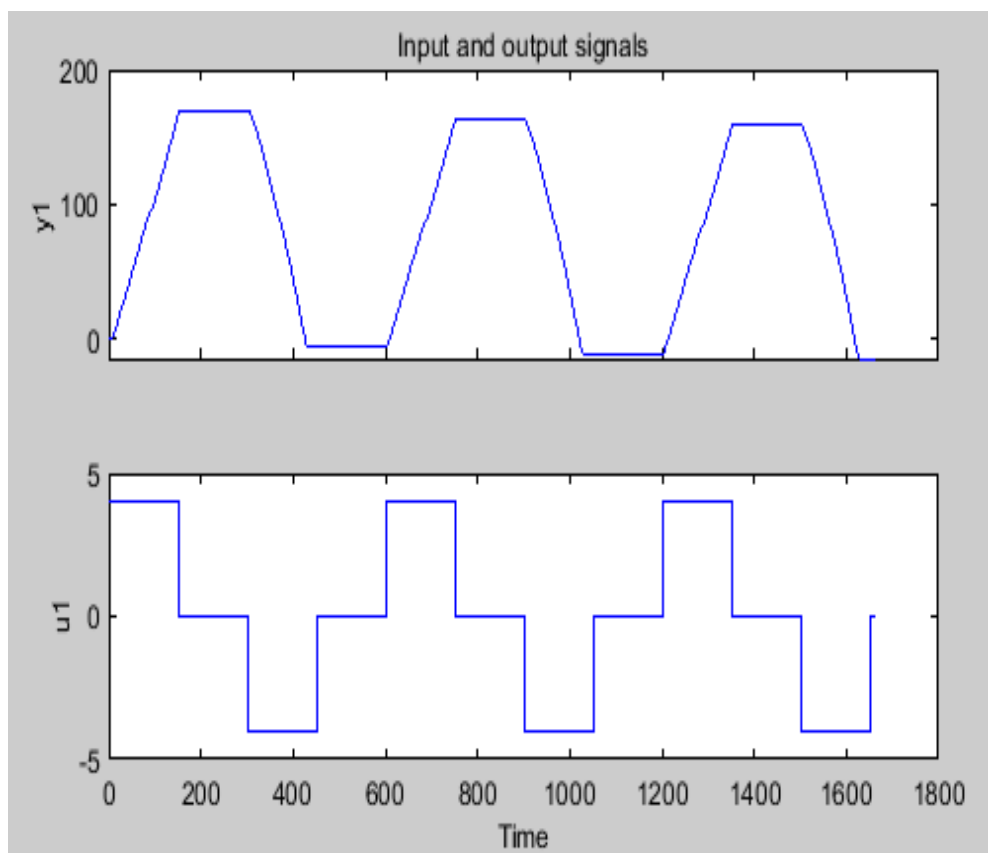

Figure 3. The plot of input and output data

\section{Model structure selection and estimation}

There are a few structures of the parametric model that can be used to describe the system, such as AutoRegressive with Exogenous Input (ARX), Auto-Regressive Moving Average with Exogenous Input (ARMAX), Output Error (OE), and Box-Jenkins (BJ) model. 


\section{AutoRegressive with Exogenous Input (ARX) Model}

The ARX model shown in Figure 4 is the easiest model to integrate a stimulus signal. Moreover, the estimation of the ARX model is the most effective method of polynomial estimation since it is the product of the solution of linear regression equations in analytics.

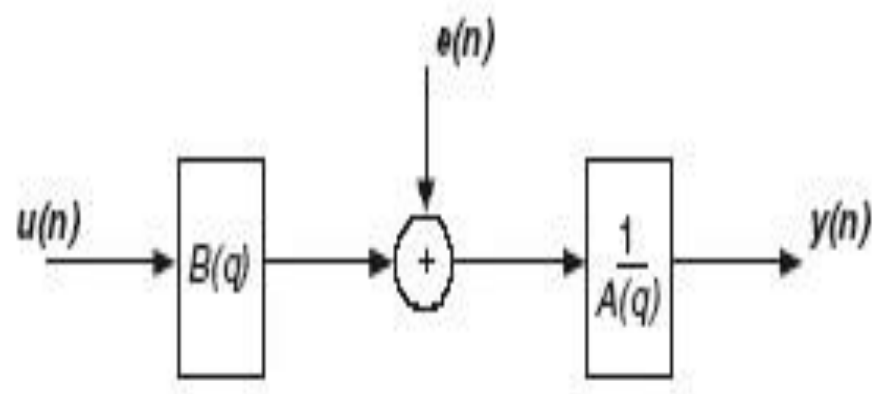

Figure 4. ARX Model Structure

The ARX model structure can be written as in (1):

$$
\mathrm{y}(k)=\frac{B(q)}{A(q)} u(k)+\frac{1}{A(q)} e(k)
$$

where $y(k)$ is the output at time $k, u(k)$ is the input at time $k$, and $e(k)$ is the error signal at time $k$.

\section{AutoRegressive Moving Average with Exogenous Input (ARMAX) Model}

The ARMAX form, in comparison to the ARX model, involves disturbance dynamics. ARMAX models are helpful if you have dominant disturbances, such as at the input, entering early. The ARMAX Model Structure is depicted in Figure 5.

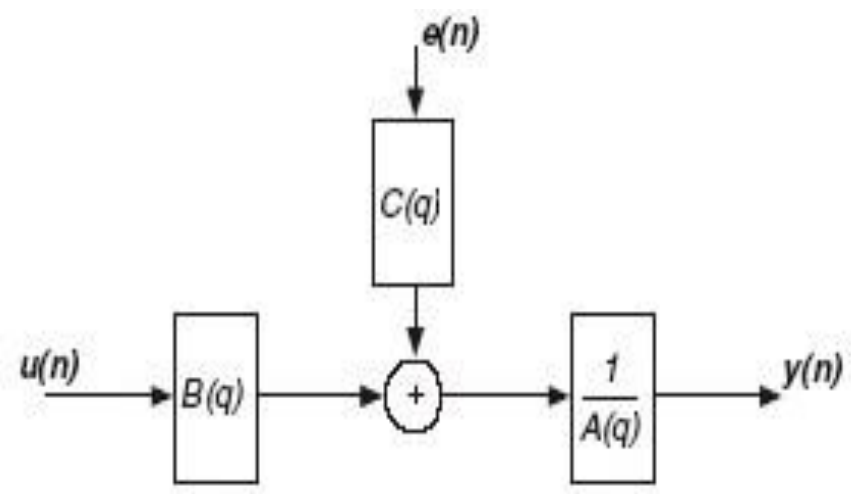

Figure 5. ARMAX Model Structure

The ARMAX Model Structure as in (2):

$$
\mathrm{y}(k)=\frac{B(q)}{A(q)} u(k)+\frac{C(q)}{A(q)} e(k)
$$

\section{Box-Jenkins (BJ) Model}

The Box-Jenkins (BJ) configuration offers a complete model of disturbance properties modelling independently from device dynamics. When have disruptions come late in the process, the Box-Jenkins model is beneficial. Figure 6 shows the Box-Jenkins Model Structure. 


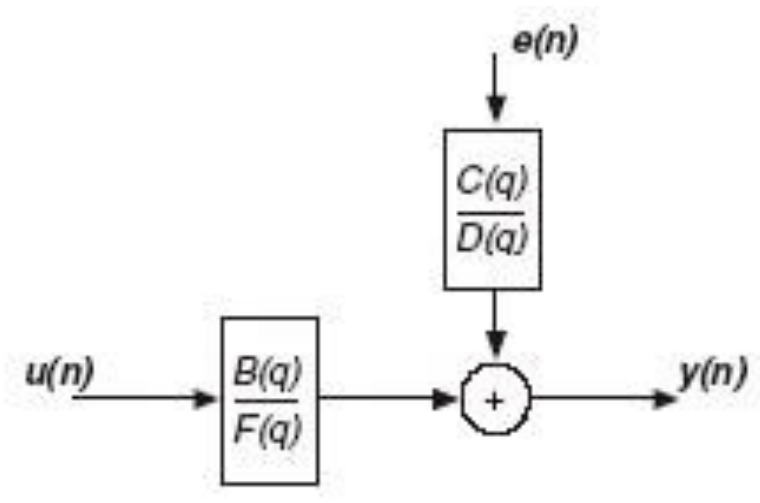

Figure 6. Box-Jenkins Model Structure

The BJ Model Structure as in (3):

$$
\mathrm{y}(k)=\frac{B(q)}{F(q)} u(k)+\frac{C(q)}{D(q)} e(k)
$$

\section{Output-Error (OE) Model}

The model configuration Output-Error (OE) explains machine dynamics individually. The disruption properties are not modelled using parameters. The OE Model Structure is shown in Figure 7.

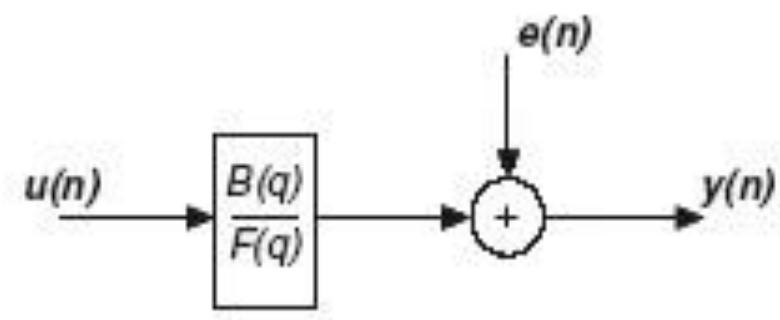

Figure 7. OE Model Structure

The OE Model Structure as in (4):

$$
\mathrm{y}(k)=\frac{B(q)}{F(q)} u(k)+e(k)
$$

\section{Hammerstein Model}

The basic structure of a Hammerstein model consists of a static nonlinear block and linear dynamic block in a cascade [17, 18], as illustrated in Figure 8. The Hammerstein Structure as in (5):

$$
\mathrm{y}(k)=Z^{-d} \frac{B(q)}{A(q)} u(k)+e(k)
$$

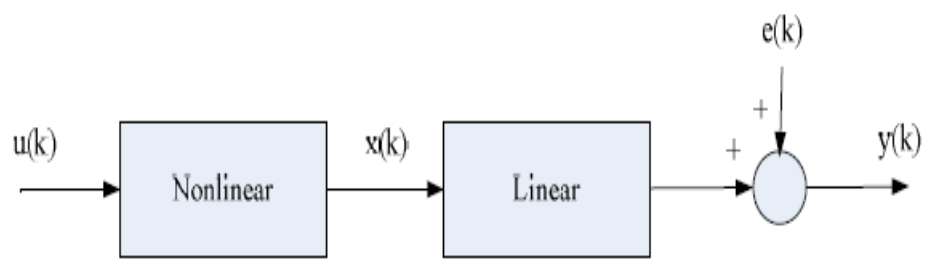

Figure 8. OE Model Structure 


\section{Model validation}

The validation process is the next step after an appropriate model estimate and structure is selected. In this stage, the validity of measured and desired data was tested under a validation criterion. In order to show the accuracy of the estimated model relative to the real plant, better fitting parameters were used. According to Ljung [13], the model would be approved if the best fit is $90 \%$ or higher.

$$
f i t=100\left[1-\frac{\operatorname{norm}(\hat{y}-y)}{\operatorname{norm}(y-\bar{y})}\right] \%
$$

where $y$ is true value, $\hat{y}$ is approximate value and $\bar{y}$ is mean value.

It may also be necessary to accept or deny those received models using Akaike's Final Prediction Error (FPE). The collection of the model from different orders can be made based on the smallest FPE value.

$$
F P E=V \frac{\left(1+n_{a} / N\right)}{\left(1-n_{a} / N\right)}
$$

where $\mathrm{V}$ is loss function, $n_{a}$ is number of approximated parameters, and $\mathrm{N}$ is a number of samples.

\section{RESULTS AND DISCUSSION}

The research introduces models for the Intelligent Pneumatic Actuator (IPA) system using the system identification method. The purpose of this analysis is to model the whole IPA system using ARX, ARMAX, Box-Jenkins, output-error, and Hammerstein model structures and compare between them.

The MATLAB System Identification Toolbox provides information about the models (i.e. discrete-transfer function, fit to estimation data, FPE, MSE, etc.). For example, the discretetime of ARX, ARMAX, Box-Jenkins, output-error and Hammerstein models are shown in the (8), (9), (10), (11), and (12), respectively.

ARX Model:

$$
\begin{aligned}
& \mathrm{A}\left(\mathrm{Z}^{-1}\right)=1-2.99 \mathrm{Z}^{-1}+2.981 \mathrm{Z}^{-2}-0.9917 \mathrm{Z}^{-3} \\
& \mathrm{~B}\left(\mathrm{Z}^{-1}\right)=0.1187 \mathrm{Z}^{-1}-0.235 \mathrm{Z}^{-2}+0.1169 \mathrm{Z}^{-3}
\end{aligned}
$$

$$
\mathrm{A}\left(\mathrm{Z}^{-1}\right)=1-2.861 \mathrm{Z}^{-1}+2.723 \mathrm{Z}^{-2}-0.8614 \mathrm{Z}^{-3}
$$

ARMAX Model: $\quad \mathrm{B}\left(\mathrm{Z}^{-1}\right)=0.1899 \mathrm{Z}^{-1}-0.23391 \mathrm{Z}^{-2}+0.1493 \mathrm{Z}^{-3}$

$$
C\left(Z^{-1}\right)=1-1.181 Z^{-1}+0.1841 Z^{-2}-0.003272 Z^{-3}
$$

$$
\mathrm{B}\left(\mathrm{Z}^{-1}\right)=0.2463 \mathrm{Z}^{-1}-0.1306 \mathrm{Z}^{-2}
$$

BJ Model:

$$
\begin{aligned}
& C\left(Z^{-1}\right)=1-0.1806 Z^{-1}-0.02334 \mathrm{Z}^{-2} \\
& \mathrm{D}\left(\mathrm{Z}^{-1}\right)=1-1.1877 \mathrm{Z}^{-1}+0.88 \mathrm{Z}^{-2}
\end{aligned}
$$$$
\mathrm{F}\left(\mathrm{Z}^{-1}\right)=1-1.598 \mathrm{Z}^{-1}+0.5984 \mathrm{Z}^{-2}
$$

$\begin{array}{ll} & \mathrm{B}\left(\mathrm{Z}^{-1}\right)=0.1899 \mathrm{Z}^{-1}-0.3391 \mathrm{Z}^{-2}+0.1493 \mathrm{Z}^{-3} \\ \text { OE Model: } & \mathrm{F}\left(\mathrm{Z}^{-1}\right)=1-2.861 \mathrm{Z}^{-1}+2.723 \mathrm{Z}^{-2}-0.8614 \mathrm{Z}^{-3}\end{array}$ 


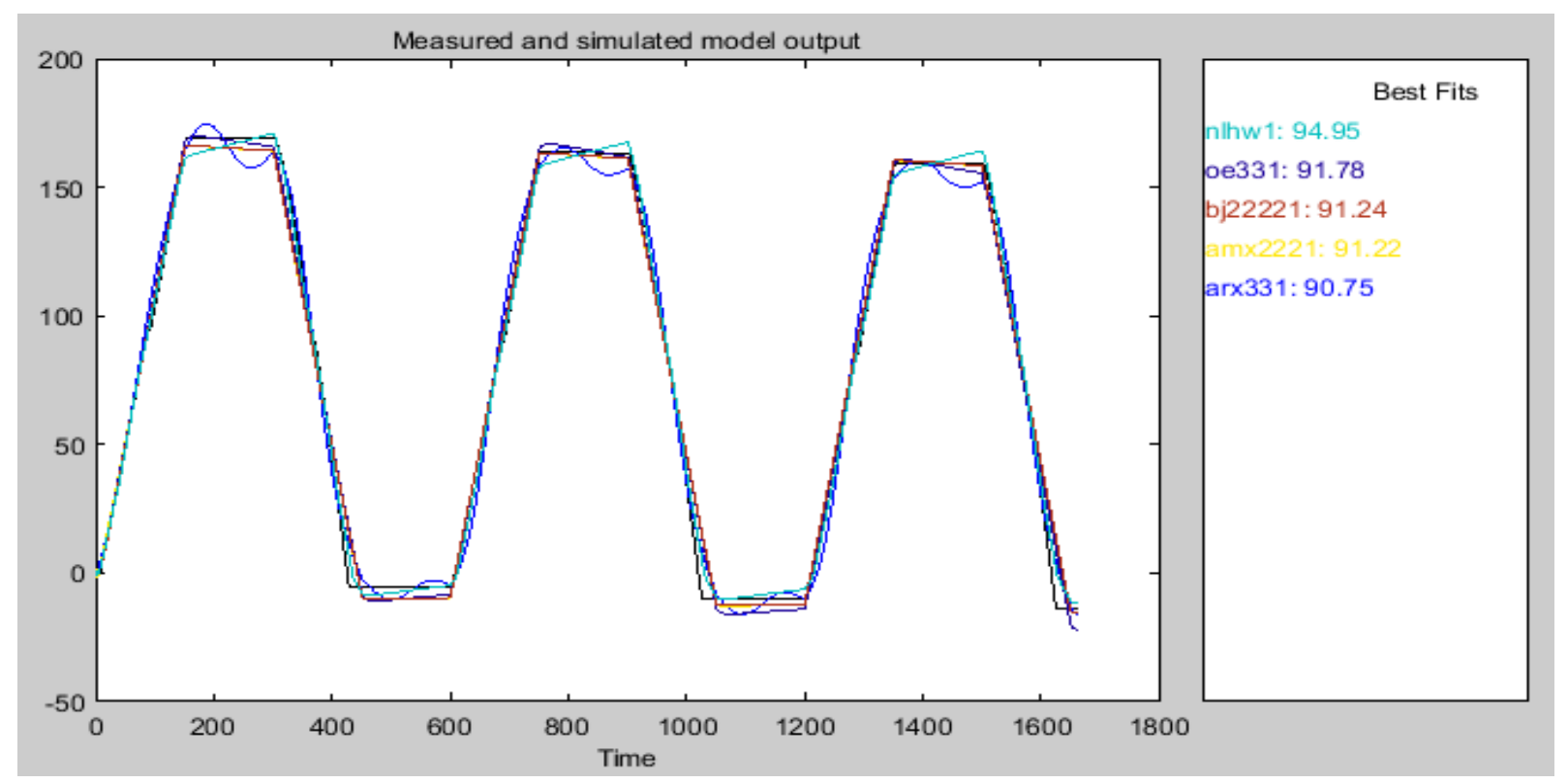

Figure 9. The output fittings for a developed ARX model

From the model output shown in Figure 9, it is apparent that the Hammerstein model is similar to the actual plant and give the highest best fit value. Compared to Hammerstein models, the losses of $9.25 \%$ of ARX, $7.22 \%$ of ARMX, $8.22 \%$ of BJ, $9.29 \%$ of OE, and $5.05 \%$ of compared to Hammerstein models are most likely caused by dead zone, friction, air leakage, etc. in IPA system.

Model output in terms of the percentage of best fit and final prediction error (FPE) is summarized and reported as shown in Table 1.

Table 1. Model Validation Values

\begin{tabular}{cccccc}
\hline Criteria & ARX & ARMX & BJ & OE & Hammerstein \\
\hline Best Fit (\%) & 90.75 & 91.22 & 91.24 & 91.78 & 94.95 \\
FPE & 0.04293 & 0.03073 & 0.03641 & 33.97 & 18.81 \\
\hline
\end{tabular}

Each model has been tested in the best fit and final prediction error in order to confirm acceptance. Table 1 indicates that all models have provided the best fit, but the Hammerstein model has succeeded in producing a better fit than other models. This condition shows that the models ARX, ARMX, BJ, OE and Hammerstein effectively reflect the actual IPA scheme used in this analysis.

\section{CONCLUSION}

This paper introduces versions of the Intelligent Pneumatic Actuator (IPA) model using ARX, ARMAX, Box-Jenkins, Output-Error, and Hammerstein models. The model of the IPA system used in this analysis was developed using an experimental method known as the system identification technique. The effects were evaluated based on the most acceptable output. The most significant finding from this research is that, relative to other models, the analysis of the simulation outcome based on the SI technique shows that the percentage of best fit for the Hammerstein model structure is $94.95 \%$, which is greater than ARX, ARMAX, OE, and BJ. In comparison, with the best fit of more than 90\%, ARX, ARMAX, OE, and BJ have decent performance. Future analysis of the appropriate controller to improve the transient response of the IPA positioning system will be considered as the next stage of this study. 


\section{ACKNOWLEDGEMENT}

The authors would like to acknowledge the support provided by the Ministry of Higher Education (MOHE) and Universiti Teknologi Malaysia (UTM) Collaborative Research Grant (CRG), Grant No. 08G30 and 08G31.

\section{REFERENCES}

[1] K. Osman, A. A. M. Faudzi, M. F. Rahmat, N. D. Mustafa, M. A. Azman, and K. Suzumori, "System Identification model for an Intelligent Pneumatic Actuator (IPA) system," IEEE Int. Conf. Intell. Robot. Syst., pp. 628-633, 2012, doi: 10.1109/IROS.2012.6385751.

[2] K. Osman, A. A. M. Faudzi, M. F. Rahmat, N. D. Mustafa, A. F. Z. Abidin, and K. Suzumori, "Proportional-integrative controller design of Pneumatic system using particle swarm optimization," Proceeding - 2013 IEEE Student Conf. Res. Dev. SCOReD 2013, no. December, pp. 421-426, 2013, doi: 10.1109/SCOReD.2013.7002623.

[3] K. Osman, A. 'Athif M. Faudzi, M. F. Rahmat, O. F. Hikmat, and K. Suzumori, "Predictive Functional Control with Observer (PFC-O) Design and Loading Effects Performance for a Pneumatic System," Arab. J. Sci. Eng., vol. 40, no. 2, pp. 633-643, 2015, doi: 10.1007/s13369-014-1421-z.

[4] K. Suzumori, J. Tanaka, and T. Kanda, "Development of an intelligent pneumatic cylinder and its application to pneumatic servo mechanism," IEEE/ASME Int. Conf. Adv. Intell. Mechatronics, AIM, vol. 1, pp. 479-484, 2005, doi: 10.1109/aim.2005.1511028.

[5] A. À. M. Faudzi, K. Suzumori, and S. Wakimoto, "Development of Pneumatic Actuated Seating System to aid chair design," IEEE/ASME Int. Conf. Adv. Intell. Mechatronics, AIM, pp. 1035-1040, 2010, doi: 10.1109/AIM.2010.5695794.

[6] E. Richer and Y. Hurmuzlu, "A high performance pneumatic force actuator system: Part I-nonlinear mathematical model," J. Dyn. Syst. Meas. Control. Trans. ASME, vol. 122, no. 3, pp. 416-425, 2000, doi: $10.1115 / 1.1286336$

[7] K. O. Siti Fatimah Sulaimana, M. F. Rahmat, A. A. M. Faudzi, "Linear and Nonlinear ARX Model for Intelligent Pneumatic Actuator Systems," J. Teknol., vol. 6, pp. 21-28, 2016, doi: 10.11113/jt.v78.5419

[8] K. Hamiti, A. Voda-Besançon, and H. Roux-Buisson, "Position control of a pneumatic actuator under the influence of stiction," Control Eng. Pract., vol. 4, no. 8, pp. 1079-1088, 1996, doi: 10.1016/09670661(96)00106-2.

[9] J. Wu, M. Goldfarb, and E. Barth, "On the observability of pressure in a pneumatic servo actuator," J. Dyn. Syst. Meas. Control. Trans. ASME, vol. 126, no. 4, pp. 921-924, 2004, doi: 10.1115/1.1850530.

[10] G. Carducci, N. I. Giannoccaro, A. Messina, and G. Rollo, "Identification of viscous friction coefficients for a pneumatic system model using optimization methods," Math. Comput. Simul., vol. 71, no. 4-6, pp. 385-394, 2006, doi: 10.1016/j.matcom.2006.02.005.

[11] L. L. and T. Glad, Modelling of Dynamic Systems, Prentice-Hall, Inc. Upper Saddle River, vol. 5.1994.

[12] D. Hanafi, M. S. Suid, M. N. Ribuan, R. Omar, M. N. M. Than, and M. F. ad Rahmat, "Speed effect to a Quarter car ARX model based on system identification," Int. J. Adv. Sci. Eng. Inf. Technol., vol. 7, no. 2, pp. 468-474, 2017, doi: 10.18517/ijaseit.7.2.1500.

[13] L. Ljung, "System identification toolbox," Matlab user's Guid., vol. 1, p. 237, 2011.

[14] A. A. M. Faudzi, K. Suzumori, and S. Wakimoto, "Design and control of new intelligent pneumatic cylinder for intelligent chair tool application," IEEE/ASME Int. Conf. Adv. Intell. Mechatronics, AIM, pp. 1909-1914, 2009, doi: 10.1109/AIM.2009.5229768.

[15] A. M. Faudzi, K. Osman, M. F. Rahmat, N. D. Mustafa, M. A. Azman, and K. Suzumori, "Nonlinear mathematical model of an Intelligent Pneumatic Actuator (IPA) systems: Position and force controls," IEEE/ASME Int. Conf. Adv. Intell. Mechatronics, AIM, pp. 1105-1110, 2012, doi: 10.1109/AIM. 2012.6266014

[16] S. F. Sulaiman, M. F. Rahmat, A. A. M. Faudzi, and K. Osman, "Disturbance rejection using Model Predictive control for pneumatic actuator system," Proceeding - 2016 IEEE 12th Int. Colloq. Signal Process. its Appl. CSPA 2016, no. March, pp. 285-290, 2016, doi: 10.1109/CSPA.2016.7515847.

[17] S. F. Sulaiman, M. F. Rahmat, A. A. M. Faudzi, K. Osman, N. H. Sunar, and S. N. S. Salim, "Hammerstein model based RLS algorithm for modeling the intelligent Pneumatic Actuator (IPA) system," Int. J. Adv. Sci. Eng. Inf. Technol., vol. 7, no. 4, pp. 1457-1463, 2017, doi: 10.18517/ijaseit.7.4.3149.

[18] A. A. M. Faudzi and N Zhang, "Analysis on the Performance of a Second-order and a Third-order RLC Circuit of PRBS Generator," Journal of Integrated and Advanced Engineering (JIAE), vol. 1, no. 1, pp. 110, 2021, doi: 10.51662/jiae.v1i1.7 